\title{
Trial Disease Assessments Supplemental Qualifiers Dataset
}

National Cancer Institute

\section{Source}

National Cancer Institute. Trial Disease Assessments Supplemental Qualifiers Dataset. NCl Thesaurus. Code C147255.

A dataset containing supplemental information, specifically non-standard variables, to parent records in the trial disease assessments domain. 